\title{
Editorial for the Journal of Hematopathology: crisis in science?
}

\author{
J. H. van Krieken
}

Published online: 22 January 2014

(C) Springer-Verlag Berlin Heidelberg 2014

There were times when doctors, professors and scientists were respected. What they said and wrote was believed to be the truth. And they themselves believed what they said and wrote because it was based on science well done. Over time, we have learned to look critically at the science industry. We have learned about scientists twisting data, we know how to lie with statistics and we know how publication bias affects our knowledge. Repeating experiments from articles published in Science and Nature showed that many did not have in the same outcome. Is there a crisis in science?

I am a doctor, professor and scientist and feel still respected enough. I know that not all I say and write is the absolute truth and I know that my best ideas have been proven wrong, often by experiments done by my own Ph.D. students. And I believe in science and progress. How naïve can one be?

In the science industry, money goes to those who have articles in the journals with the highest impact, meaning that what is written is cited rapidly and often; but rapidly is more important than often. This results in publishing fast, thinking that it is better to be fast than good. Of course, trying to solve the cancer problem is urgent, so indeed, speed is important. But good science is, maybe, more often slow science. Highquality data need large numbers, many controls and much repetition. But every good scientist knows that large numbers, many controls and much repetition kill many of the brilliant findings coming out of clever experiments.

J. H. van Krieken $(\triangle)$

Department of Pathology, Radboud University Nijmegen Medical Centre, P.O. Box 9101, 6500, HB Nijmegen, The Netherlands

e-mail: J.vankrieken@pathol.umcn.nl
Why do I still believe in science? The scientific method is the best invention of mankind. It is based on curiosity, and rigorous experimenting based on the urgency to prove that a hypothesis is wrong before accepting it. This is painstaking and disappointing work: a good scientist needs to be capable to handle many disappointments. It is, therefore, that I like to read studies with negative results, interesting case studies and studies that confirm other studies. Those studies are not very well respected and don't bring glamour and prizes but are often good science bringing about real progress. The science of hematopathology has resulted in much better diagnoses, making newer treatments possible and improving survival of patients. That is the science I see and use every day, and that makes me a believer.

The Journal of Hematopathology tries to bring science and knowledge to you in order to make progress faster. Case reports are important in this respect because they are selected on teaching value or theory-inducing quality; reviews collect new data in comprehensive knowledge and original articles bring us step by step further. The Journal of Hematopathology is one of the few journals that have an anonymous review process: reviewers do not know who the authors of an article they judge are. It is one of those small things that taught me how important reputation sometimes is in judging. Some reviewers feel lost when they see an article and do not know from whom it came. And I have seen articles from very well-known hematopathologists getting a harsh review, which was not smoothened by the reputation of the writer. Hopefully, you will enjoy this issue of the Journal of Hematopathology a little more, knowing what vision lies behind it. 